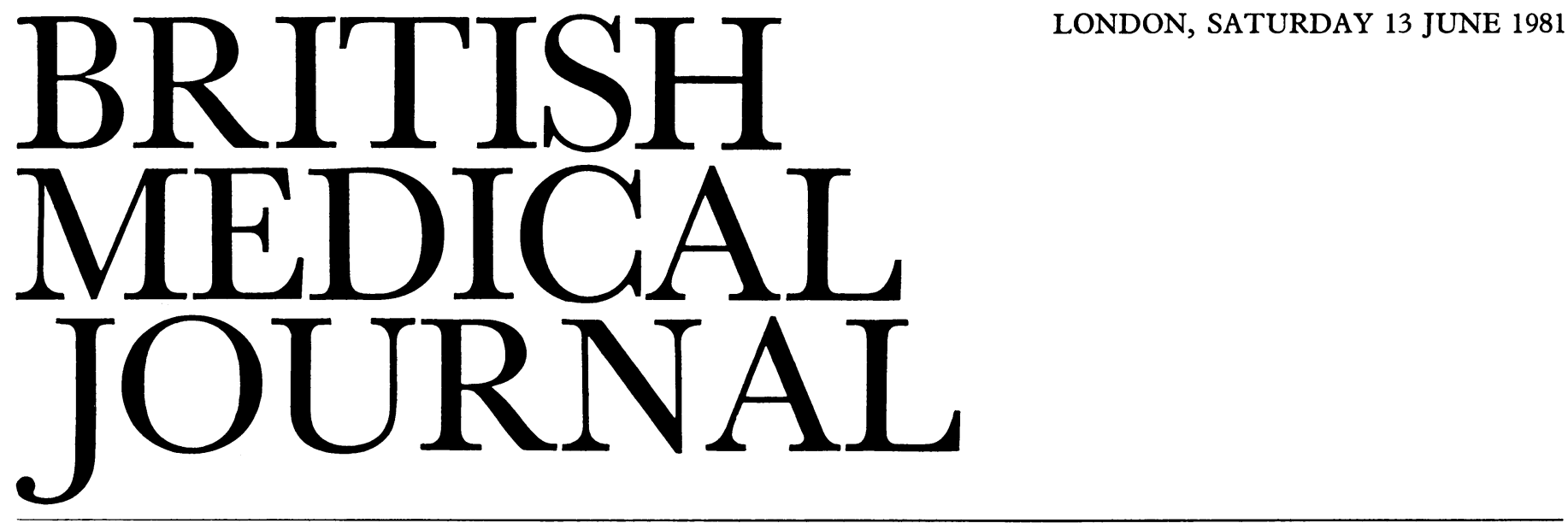

\title{
Oxygen in the home
}

Oxygen is of proved value only in treating patients with arterial hypoxaemia; the arterial oxygen pressure $\left(\mathrm{PaO}_{2}\right)$ has to be restored towards normal to ensure adequate delivery of oxygen to the body cells. Arterial hypoxaemia is shown by central cyanosis, usually recognised when the arterial oxygen saturation is below $90 \% .{ }^{1}$ Cyanosis is easily recognised in polycythaemia but is difficult to detect in anaemic patients. Arterial hypoxaemia usually results from disease that increases the proportion of the 300 million alveoli that are perfused with blood but not adequately ventilated.

Treatment with oxygen is of recognised value in many acute conditions, including pneumonia, pulmonary oedema, severe bronchial asthma, and pulmonary thromboembolism, where a low $\mathrm{PaO}_{2}$ is usually associated with a low or normal arterial carbon dioxide pressure $\left(\mathrm{PaCO}_{2}\right)$ (type I respiratory failure). ${ }^{2}$ Here giving oxygen in high concentration by mask is safe, with little risk of carbon dioxide retention. In chronic bronchitis and emphysema, however, particularly during an acute infective exacerbation, hypoxaemia is usually associated with retention of carbon dioxide; and high concentrations of oxygen can then carry a definite but unpredictable risk of exaggerating carbon dioxide retention, which can kill from respiratory acidosis. ${ }^{34}$ Providing oxygen is only a part of management of these acutely ill patients-along with the use of diuretics, antibiotics, steroids, or bronchodilators, some of which may need to be given parenterally. The complexity of the treatment, ${ }^{4}$ coupled with the need for nursing care, often requires that such acutely ill patients be admitted to hospital.

At page 1941 B T Williams describes a 10-fold variability in the provision of oxygen at home by the area health authorities in England and Wales during 1977-9. Use of oxygen was not related to the incidence of respiratory disease in these areas. He concludes convincingly that the rationale for prescribing domiciliary oxygen is ill defined. A previous survey in south-east Scotland ${ }^{5}$ gave similar results. Anecdotal evidence suggests that some patients have only a few cylinders of oxygen provided each year. Their use of oxygen must be intermittent, as the $\mathrm{F}$ size cylinder will deliver oxygen for only three to four hours at 6 litres/min or for nine to 10 hours at 2 litres/ min. Probably much of the oxygen used at home at present is given for very short periods.

Many patients ${ }^{6}$ (and possibly some doctors) believe that oxygen is indicated for relief of breathlessness-for example, after exertion. Breathlessness has many causes, ${ }^{7} 8$ but physiological evidence suggests that hypoxaemia alone is rarely the most important. An increased awareness of the demand for breathing (or breathlessness) is often associated with alveolar hyperventilation, as shown by the low $\mathrm{PaCO}_{2}$ commonly found in breathless patients with disease of the heart or lungs. Relief of hypoxaemia, however, in these patients rarely restores a normal $\mathrm{PaCO}_{2}$, implying that the increased ventilation does not result from hypoxic stimulation of chemoreceptors. Animal studies suggest that in pneumonia, pulmonary oedema, and possibly bronchial asthma hyperventilation mainly arises from stimulation of lung $\mathrm{J}$ receptors ${ }^{910}$ and has little to do with arterial hypoxaemia. Though blind studies have shown that oxygen during exercise can increase exercise tolerance in some patients with chronic bronchitis and emphysema, ${ }^{11-15}$ the value of short periods of breathing oxygen to relieve breathlessness after exertion has not been formally assessed in such a manner. On physiological grounds the value of such treatment must be doubtful-as must the value of much of the current use of oxygen in domiciliary practice.

In contrast to these doubts about the real value of the possibly widespread use of intermittent oxygen treatment at home, two reports of recent scientific trials of the efficacy of long-term continuous domiciliary oxygen treatment are now available, one by the Medical Research Council ${ }^{16}$ in Britain and the other by the US National Institutes of Health. ${ }^{17}$ Both studies screened patients carefully to include only those with persistent hypoxaemia; and though the severity of airways obstruction and pulmonary hypertension were similar in the two studies, the American patients were mostly normocapnic (mean $\mathrm{PaCO}_{2} 43 \mathrm{~mm} \mathrm{Hg} ; 5.7 \mathrm{kPa}$ ) while the British patients tended to have carbon dioxide retention (mean $\mathrm{PaCO}_{2} 50 \mathrm{~mm} \mathrm{Hg} ; 6.7 \mathrm{kPa}$ ).

In the American study ${ }^{17}$ patients were randomly assigned to continuous oxygen treatment (that is, 19 hours or more daily) or nocturnal oxygen treatment (that is, 12 hours daily); there was no control group. Follow-up was for a minimum of 12 months (mean 19.3 months) and the overall death rate in the nocturnal oxygen group was almost twice (1.95 times) as high as that in the continuous oxygen group. The benefit from continuous oxygen was most noticeable in those with more severe disability-marked by hypercapnia, raised packed cell volume, pulmonary hypertension, and severe disturbance of mood.

The British study ${ }^{16}$ compared 15 hours' nocturnal oxygen treatment with a control group given no oxygen, and survival was followed for up to five years. The results were different in men and women. In men (most patients were men) no 
improvement in survival was seen with oxygen until 500 days from the start of treatment. Thereafter the death rate in the oxygen group ( $12 \%$ a year) was less than half that of the control group (29\% a year). From the outset the mortality of the control women was significantly greater than that of the treated women.

Only cautious conclusions can be drawn from these two different studies, but prolonged oxygen treatment does seem to improve survival with severe chronic obstructive lung disease if it is given for 15 or more hours a day, the benefit being most noticeable in patients with the greatest disability. The delay in the appearance of benefit from home oxygen among the men in the British study may perhaps indicate that more patients with very severe disability had been included and that these biased the initial results.

Furthermore, prolonging life by the use of long periods of oxygen each day may not necessarily have a dramatic effect on the quality of life of these patients. Necessarily the home oxygen system in current use in Britain seriously limits the patient's mobility, for he or she must trail tubing about in a limited radius from the cylinder. The two American liquid oxygen systems are more effective means for providing portable oxygen for exercise. Even so the weight of the portable equipment may abolish any gain in mobility unless the equipment is wheeled by the patient on a shopping trolley. ${ }^{14}$

The financial implications are also important. A survey in Britain in 1961 showed that $17 \%$ of men and $8 \%$ of women aged 40-64 years had chronic bronchitis and emphysema. ${ }^{18}$ The prevalence of the disease has declined with clean air legislation, and not all bronchitics have hypoxaemia; but nearly 30 million working days are lost each year in Britain from chronic bronchitis and emphysema. ${ }^{19}$ Possibly some 10000 50000 patients in Britain might benefit from long-term oxygen treatment, but more accurate figures are urgently required. If such long-term treatment is to be offered to hypoxaemic patients, clearly the most economical and effective means must be used.

The oxygen concentrator ${ }^{20}$ seems to provide this, but at present oxygen cylinders-the most expensive way of delivering the oxygen-are the only means available through the NHS Drug Tariff. Continuous oxygen treatment for 15 or indeed 24 hours a day from the oxygen concentrator is five to seven times cheaper than the same treatment from oxygen cylinders. ${ }^{21}$ The oxygen concentrator is a device the size of a domestic refrigerator that extracts nitrogen from air, using an electric compressor. The concentrator has proved to be safe, reliable, and effective, ${ }^{17}$ and is extensively used already in North America, Dublin, ${ }^{22}$ and Birmingham. ${ }^{20}$

Now that the clinical indications for long-term oxygen treatment are becoming more clear, the NHS should surely arrange to provide this treatment by the most economical method. A second priority should be a scientific investigation of the use of intermittent transient oxygen for the relief of breathlessness such as that following exercise. Quite possibly the total cost of home oxygen treatment could be reduced if cheap and effective treatment of hypoxic chronic bronchitis is substituted for the apparently haphazard use of home oxygen that appears to prevail at present.

${ }^{1}$ Kelman GR, Nunn JF. Clinical recognition of hypoxaemia under fluorescent lamps. Lancet 1966;i:1400-3.

${ }^{2}$ Campbell EJM. Respiratory failure. Br Ned F 1965;i :1451-60.

${ }^{3}$ Donald KW. Neurological effects of oxygen. Lancet 1949;ii:1056-7.

4 Warren PM, Millar JS, Avery A, Flenley DC. Respiratory failure revisited; acute exacerbations of chronic bronchitis between 1961-68 and 1970-76. Lancet 1980; : 467-71.

${ }^{5}$ Scottish Health Services Council. Uses and dangers of oxygen therapy. Edinburgh: HMSO, 1969.
${ }^{6}$ McNeill RS, Watson JM. Oxygen therapy in the home. Br Med $\mathcal{F} 1966$; : 331-3.

${ }^{7}$ Howell JBL, Campbell EJM, eds. Breathlessness. Oxford: Blackwell Scientific Publications, 1966.

${ }^{8}$ Porter R, ed. Breathing: Hering Breuer centenary symposium. London: $\mathrm{J}$ and A Churchill, 1970. (Ciba Foundation Symposium.)

9 Paintal AS. Vagal sensory receptors and their reflex effect. Physiol Rev $1973 ; 53: 159-227$.

10 Trenchard D, Gardner D, Guz A. Role of pulmonary vagal afferent nerve fibres in the development of rapid shallow breathing in lung inflammation. Clin Sci 1972;42:251-63.

11 Cotes JE. Respiratory function and portable oxygen therapy in chronic non-specific lung disease in relation to prognosis. Thorax 1960;15: 244-51.

12 Vyas MN, Banister EW, Morton JW, Grzybowski S. Response to exercise in patients with chronic airway obstruction. Am Rev Respir Dis 1971; $103: 401-12$.

13 Bradley BL, Garner AE, Billiu D, Mestas JM, Forman J. Oxygen-assisted exercise in chronic obstructive lung disease. The effect on exercise capacity and arterial blood gas tension. Am Rev Respir Dis 1978;118:239-43.

14 Leggett RJE, Flenley DC. Portable oxygen and exercise tolerance in patients with chronic hypoxic cor pulmonale. Br Med 7 1977;ii:84-6.

15 Woodcock AA, Gross ER, Geddes DM. Oxygen relieves breathlessness in "pink puffers." Lancet $1981 ; \mathrm{i}: 907-9$.

${ }^{16}$ Medical Research Council Working Party. Long-term domiciliary oxygen therapy in chronic hypoxic cor pulmonale complicating chronic bronchitis and emphysema. Lancet $1981 ; \mathrm{i}: 681-6$.

17 Nocturnal oxygen therapy trial group. Continuous or nocturnal oxygen therapy in hypoxemic chronic obstructive lung disease. A clinical trial. Ann Intern Med 1980;93:391-8.

18 Respiratory Diseases Study Group of the College of General Practitioners. Chronic bronchitis in Great Britain. Br Med 71961 ;ii:973-9.

${ }^{19}$ Royal College of Physicians. Report of the Committee on Thoracic Medicine. Disabling chest disease: prevention and care. $\mathcal{F} R$ Coll Physicians Lond 1981;15:3-20.

20 Stark RD, Bishop JM. New method for oxygen therapy in the home using an oxygen concentrator. $\mathrm{Br}$ Med 7 1973; ii:105-6.

${ }^{21}$ Lowson K, Drummond MF, Bishop JM. Costing new services: long-term domiciliary oxygen therapy. Lancet $1981 ; \mathrm{i}: 1146-9$.

${ }^{22}$ Callaghan B. Long-term low flow oxygen in the management of chronic pulmonary insufficiency. Irish Medical Times 1979; 28 September: $16-17,19$.

\section{Obstetric training and general practitioners}

Medical education has changed considerably in Britain over the past 20 years. It is now accepted that the undergraduate period is but the beginning, with an obligation to undertake further training before full registration. Even then the doctor will practise under supervision for a varying number of years depending on his chosen specialty. This broader, long-term view of training has led to appreciable pruning in the undergraduate years, with certain major and long-established disciplines cutting back their teaching programmes on the understanding that the young doctor will receive further instruction under supervision. In the sense that preregistration posts are predominantly in the medical or surgical wards there is the opportunity for physicians and surgeons to reinforce and amplify the teaching they have given in the clinical years of the undergraduate curriculum. This is not the case in obstetrics, which is widely held to be too specialised for inclusion in the preregistration year. Hence at the time of full registration most, if not all, young doctors have no more experience of obstetrics than was offered during the time they were medical students.

The recommendations of the General Medical Council about obstetrics in the undergraduate curriculum are that: "The teaching should include instruction in the principles of human reproduction and family planning and in the principles and practice of normal obstetrics. The teaching should emphasise antenatal and postnatal care, the management of normal labour and its complications, the impact of 